\title{
MASSIFICAÇÃO HUMANA E A EDUCAÇÃO ARISTOCRÁTICA EM NIETZSCHE
}

\author{
HUMAN MASS AND ARISTOCRATIC \\ EDUCATION IN NIETZSCHE
}

Samuel Mendonça ${ }^{1}$

\begin{abstract}
Resumo
A vida aristocrática indica a educação individual, a educação da solidão e a educação do destaque, que requer a autocrítica como elemento para a autossuperação da grande individualidade. Portanto, não se trata de uma educação para todos, mas para os que têm reverência por si mesmos. Neste artigo, pretendemos apresentar as razões que fundamentam a educação aristocrática em Nietzsche e que encontram sentido na compreensão do mesquinho, do medroso, do estúpido, na massificação humana. Para este exame, a contextualização dos condicionantes da massificação e do aprisionamento humanos encontra espaço. A metodologia utilizada na investigação consiste na revisão bibliográfica, dado que se trata de pesquisa filosófica da educação. Os resultados encontrados apontam para a necessidade de um novo perfil de homem, capaz de superar esse estado de pequenez, mesquinharia e medo.
\end{abstract}

Palavras-chave: Friedrich Nietzsche. Educação aristocrática. Massa. Medo.

\begin{abstract}
The aristocratic life indicates the individual education, education of loneliness and education of distinction that requires self-criticism as an element for self-overcoming of the great individuality. Therefore it is not about an education for everybody but for the ones that have reverence for themselves. In this article we intend to present the reasons that base an aristocratic education in Nietzsche which make sense in the comprehension of the pettiness, the fearful, the stupid, in the human mass. For this analysis the context of the conditioning of imprisonment and human mass education find space. The used methodology in the investigation consists in the bibliographical research, once it is a philosophic research on education. The outcome results point to the need of a new man's profile capable of getting over the state of insignificance, pettiness and fear.
\end{abstract}

Keywords: Friedrich Nietzsche. Aristocratic education. Mass. Fear.

\section{INTRODUÇÃO}

A educação aristocrática em Nietzsche nasce de seu aristocratismo, na acepção de "pertencer a uma elite, ser de uma exceção" (NIETZSCHE, 2007, p. 295)². Assim, fica excluída de imediato a possibilidade de uma educação vulgar por meio da aristocracia; aliás, tratar-se-ia de uma contradição. A palavra aristocracia tem origem no termo grego aristós, que

\footnotetext{
${ }^{1}$ Doutor em Filosofia da Educação/Unicamp. Coordenador e professor permanente do Programa de PósGraduação Stricto Sensu em Educação da PUC Campinas. Membro do International Network of Philosophers of Education - INPE - e do Philosophy of Education Society - PES. E-mail: samuelms@gmail.com - Campinas, São Paulo, Brasil.

${ }^{2}$ Os fragmentos póstumos aqui utilizados tiveram como base a tradução de Melo Sobrinho (2007). Trata-se de traduções das Euvres philosophiques complètes, de Friedrich Nietzsche, organizadas por Giorgio Colli e Mazzino Montinari. Essas traduções requerem uma acurada revisão.
} 
conota exceção, excelência, destaque, significando aquilo que se diferencia do vulgo; e também no termo cratios, que significa direção, gestão, governo. O ponto de partida da educação aristocrática em Nietzsche é a vida aristocrática, que se efetiva por meio da vida solitária, e cujo sentido mais preciso seria "gestão da exceção". A vida aristocrática indica a educação individual, educação da solidão e do destaque, que requer a autocrítica como elemento para a autossuperação da grande individualidade. Portanto, não se trata de uma educação para todos, mas para os que têm reverência por si mesmos.

Neste artigo pretendemos apresentar elementos que geram a massificação e o aprisionamento humanos, fundamentando o apontamento da educação aristocrática em Nietzsche, que nasce de seu aristocratismo. São terrenos férteis da educação da exceção o medo, a mesquinharia e a estupidez humanos, o que não significa dizer que a educação aristocrática existe em virtude desses elementos. O que sublinharemos neste artigo é que a educação aristocrática se confronta com um tipo de homem e sociedade, o medroso, mas que, paradoxalmente, este tipo é fundamental para o sentido desta educação; então, não se trata de aniquilar o estado de entorpecimento humano, fundado na pequenez e na mesquinharia, mas de criticar a sociedade do vulgo que se curva antes do posicionamento singular no mundo.

Embora não se possa preterir da vida social as amarras que condicionam e aprisionam o homem no mundo, deve-se refletir sobre as razões que justificam o adormecimento humano. A educação aristocrática diferencia-se da educação de rebanho e, por esta razão, tratamos de alguns dos condicionantes do vulgo. As amarras sociais, como evidenciaremos a seguir, exprimem a proposição da educação aristocrática, que se dá, paradoxalmente, no contexto do aprisionamento da vida coletiva. A educação aristocrática não pretende acabar com o adormecimento social ou com a vida coletiva; trata-se da educação da individualidade, educação que se pauta na diferença, educação do destaque.

São três os períodos da produção intelectual de Nietzsche. O terceiro e mais produtivo período (ALMEIDA, 2008), que tem sua gênese com Aurora e A gaia ciência, foi aquele no qual nos apoiamos como marco teórico, especialmente os fragmentos póstumos (Nachlass).

\section{PROPEDÊUTICA DA MASSIFICAÇÃO E DO APRISIONAMENTO HUMANOS}

A construção da educação aristocrática em Nietzsche tem como ponto de partida elementos que dizem respeito ao adormecimento do homem, à sua ignorância no mundo e ao nivelamento de sua condição como massa. Que razões justificam o aprisionamento e a 
massificação do homem no mundo? $\mathrm{O}$ que sustenta o discurso de igualdade frente à percepção da desigualdade dos indivíduos?

Aprisionamento do homem significa, em primeiro lugar, o estado de distanciamento de suas potências intelectuais e afetivas. Massificação designa a generalização da inação racional do indivíduo em sociedade, que produz o vulgo. Para Nietzsche, a massa é o "homem doméstico e o homem domesticado" (NIETZSCHE, 2007, p. 209); então, a domesticação indica a ausência de ação desse homem no mundo. Em outros termos, quando muitos indivíduos agem sem um cuidadoso uso da razão - não nos referimos à razão instrumental, razão da ciência moderna ou do método científico, mas ao $\lambda o ́ \gamma o \varsigma-$, podemos dizer que a massificação está presente.

O aprisionamento a que nos referimos é simbólico, ou seja, o homem não está necessariamente enclausurado na prisão; contudo, está amarrado, preso, estagnado na sociedade dormente. O curioso é que o homem é vontade de potência, ou seja, o homem é indeterminação, ele é um conjunto de forças internas que se superam continuamente; mesmo assim, os condicionantes da educação de rebanho parecem amarrar, aprisionar e estagnar esse indivíduo.

Esse estado social condiciona o sujeito a ser "receptor" daquilo que está pronto, preparando-o para consumir o que recebe. Dito de outro modo, trata-se do aprisionamento que produz a mentalidade do consumo e a satisfação das necessidades materiais em sociedade, e nada além disso. Construir novos valores para a existência é algo que não faz parte da vida do aprisionado, do vulgo. A concepção de uma educação aristocrática em Nietzsche nasce e se exprime neste contexto, ao menos a partir de Jenseits von Gut und Böse (1999)/Além do bem e do mal (1992), obra que apontou o filósofo como aquele capaz de construir novos valores. A educação aristocrática contrapõe-se à sociedade massificada, o que não significa dizer que se trata de alternativa messiânica para o aprisionamento do homem no mundo. A educação aristocrática é tida, para o filósofo, da mesma forma que os adormecidos têm a educação de rebanho.

Então, o aprisionamento do homem no mundo é consequência da vida dos adormecidos e não se produz como fruto da ingerência da educação formal, do Estado ou da família, embora esses institutos possam aproveitar a ignorância humana para realizar os seus propósitos. O aprisionamento do homem também se coloca na perspectiva da vontade de potência; então, o vulgo busca a sua superação, busca a dominação. Nesse sentido, não tratamos de oposição entre o filósofo, de um lado, e o vulgo, de outro. Destacamos os 
aspectos de massificação humanos apenas e tão somente com o objetivo de mostrar que a educação aristocrática se distancia desse perfil; afinal, poucos são aqueles que desejam o rigor e a dureza consigo próprios. Poucos são os que desejam fazer uma escolha diferente daquela que é fácil e esperada pela maioria. É nesse sentido que Nietzsche assevera que a receita para fazer o que a "massa chama de um grande homem é fácil. [...] Procure-se qualquer coisa que lhe seja muito agradável, ou então ponha-se na cabeça dela (da massa) que isto ou aquilo lhe será muito agradável, depois se ofereça isto a ela" (NIETZSCHE, 2007, p. 193). Poucos na sociedade têm forças para resistir à vulgaridade de ser gado, justificando o aprisionamento e a massificação humanos.

A educação aristocrática em Nietzsche não se aplica, portanto, a qualquer homem; aplica-se à grande e nobre individualidade. Essa educação destina-se àqueles que desejam se autossuperar, e isso requer um esforço individual, sugere a vida solitária e implica na busca de si mesmo.

\section{MEDO, MESQUINHARIA E PEQUENEZ: TERRENO FÉRTIL PARA A EDUCAÇÃO ARISTOCRÁTICA}

A primeira razão que manifesta o aprisionamento do homem no mundo e aponta para a necessidade da educação aristocrática é o medo de ser ele mesmo. Mas o que é o homem para Nietzsche? A resposta mais direta e objetiva a esta pergunta nuclear da educação aristocrática pode ser formulada em poucas palavras: o homem é vontade de potência. $\mathrm{O}$ que significa ter medo de ser vontade de potência? De forma simplificada, podemos dizer que ter medo de ser vontade de potência significa a tentativa de distanciamento das forças em conflito que estão presentes no humano e na natureza, embora não se possa fugir das forças em oposição que geram indeterminação. Der Wille zur Macht refere-se ao conjunto de forças internas e externas, forças que buscam se superar continuamente na destruição. $\mathrm{O}$ medo do conflito interno de forças gera o aprisionamento do homem no mundo. Assim, o homem comum apoia-se no outro homem, distanciando-se dele mesmo, dos conflitos possíveis da vida e, enfim, das forças de destruição, que também são as forças de construção. É nesse sentido que a vida social conta com a preferência do homem em relação à solidão. É assim igualmente que ele tem medo do silêncio, conforme constata Nietzsche:

Tememos, quando estamos sós e silenciosos, que algo nos seja murmurado no ouvido, e é por isso que detestamos o silêncio e nos aturdimos com a vida em sociedade. O homem se livra ainda mais da visão do sofrimento que ele mesmo experimentou; fixando para si objetivos sempre novos, ele procura esquecer o que se estende atrás de si (NIETZSCHE, 2007, p. 65). 
Por isso o povo prefere a vida social à vida individual e solitária. A vida coletiva propicia a projeção de forças e fraquezas de um no outro, de modo a permanecer distante de si e, portanto, sem a singularidade que pode justificar uma vida decente, autêntica e singular. É bem verdade que a vida social poderia almejar a autonomia, a emancipação e a liberdade, se a individualidade fosse aguçada, estimulada; então, não se trata de uma crítica à vida social, propriamente dita, mas à ausência da qualidade individual da vida social. $\mathrm{O}$ aprisionamento humano está, portanto, no medo que o indivíduo tem de ser vontade de potência.

Em outras palavras, a vida solitária é aquela na qual o sujeito tem a possibilidade de se perceber como vontade de potência e não ser confundido com o vulgo. Mas essa vida, como mostra Nietzsche, gera medo. O desconhecido, o estranho e o diferente provocam medo. Então, ao mesmo tempo que temos a possibilidade da vida singular e dinâmica, a opção da maioria é pela vida humana, demasiado humana. Vida sem vida, porque não vivida pela individualidade. O medo distancia o sujeito dele mesmo, quer dizer, da possibilidade de destruição do que é, e promove a vida social inautêntica, o que não significa que a vida autêntica aqui pensada seja boa, mas sim carregada de forças e de pulsões que não cessam de se superar continuamente.

É nesse contexto que a educação aristocrática se exprime para Nietzsche: uma educação que sugere o desejo de ser duro consigo mesmo, educação do destaque que reivindica a busca do fortalecimento de si, uma educação para poucos, pouquíssimos homens. Uma educação para os que desejam superar o medo, para aqueles que desejam a solidão, o silêncio, a fim de se autossuperarem para a revaloração de valores. De fato, não se trata de uma educação para o homem comum, que prefere a ilusão do viver sem vida, ou seja, sem o dinamismo natural da vivência; homem que opta pela ilusão do ser pelo não ser, ou seja, prefere acreditar e dar sentido ao vazio em vez de criar e produzir valores e, também, prefere pertencer à massa em vez de viver a solidão. Em uma palavra: dá preferência à educação de rebanho. Nietzsche afirma que "é duro ver os homens serem incluídos, cruamente e sem metáforas, entre os animais; e não se estará longe de nos imputar o crime de aplicar aos defensores das 'ideias modernas' os termos 'rebanho', 'instinto gregário' e outros do mesmo gênero" (NIETZSCHE, 2007, p. 200). Embora o contexto e o alvo de Nietzsche digam respeito à Europa de seu tempo, a analogia com a atualidade, inclusive a brasileira, parece-nos adequada. O homem de seu tempo tinha medo de buscar ser ele mesmo pelos 
condicionamentos do contexto da hegemonia da Prússia ${ }^{3}$. Conseguia, no máximo, realizar tarefas. A atualidade dos escritos do filósofo do eterno retorno parece inegável. Ainda sobre o medo de si, Nietzsche ironiza:

[...] há muitas morais atualmente: o indivíduo escolhe involuntariamente aquela que lhe é mais útil (ele tem de fato medo de si próprio), quer dizer, ele acolhe necessariamente o erro, na medida em que é um animal mais ou menos perigoso. Antigamente, quando os homens de uma mesma raça eram iguais, também Uma só moral bastava. Agora, os homens são muito desiguais entre si! Há mais indivíduos como jamais houve, que não se tenha ilusões! Mas eles não são tão pitorescos e tão sumariamente visíveis quanto eram antes (NIETZSCHE, 2007, p. 141, grifos do autor).

Então, o medo de si está posto para os indivíduos não pela diversidade moral; aliás, a ironia do filósofo, de que houve igualdade entre os homens de uma mesma raça, aponta para o seu limite, qual seja, a desigualdade entre os homens. De fato, o medo de si indica o perfil mesquinho e pequeno do humano e também justifica o seu adormecimento.

O segundo aspecto que parece justificar a massificação e o aprisionamento do homem no mundo, e que também acaba por anunciar a necessidade da educação aristocrática, diz respeito à natureza do homem comum. Mesquinharia, pequenez e incapacidade são atributos do vulgo. Não é difícil encontrar pessoas com esse perfil, inclusive extrapolando o contexto histórico e teórico em que Nietzsche se situa, o que, mais uma vez, confirma a sua atualidade.

Um sistema educacional construído para as massas não poderia criar resultados singulares. Entendemos por resultados singulares aqueles que poderiam indicar as condições de desenvolvimento de indivíduos determinados, sejam intelectivos, psíquicos ou físicos, e não de dados estatísticos que revelam as habilidades e as competências dos estudantes ${ }^{4}$. Natural, portanto, que tenhamos esse perfil mesquinho e insano de estudantes na educação de rebanho, da mesma forma que a sua incapacidade de questionamento dos métodos educacionais está presente. Entendemos que a inaptidão para o questionamento do significado

\footnotetext{
${ }^{3}$ Adiantamos que esse contexto hegemônico produziu a cultura filisteia, que Nietzsche critica duramente. Marton (2006) explica, com propriedade, que "o termo 'filisteu', que já aparece na Bíblia, passou a ser empregado no século XVIII, nos meios universitários alemães, para designar os estritos cumpridores das leis e dedicados executores dos deveres que execravam a liberdade gozada pelos estudantes. Personagem de bom senso, inculto em questões de arte e crédulo na ordem natural das coisas, o 'filisteu' recorria ao mesmo raciocínio para tratar das riquezas mundanas e das culturais. O poeta Heine diria que ele pesava, na sua balança de queijos, 'o próprio gênio, a chama e o imponderável'. Ao formular a expressão 'filisteus da cultura' é nessa mesma direção que Nietzsche caminha" (MARTON, 2006, p. 18).

${ }^{4}$ As exigências do Ministério da Educação impõem um ritmo frenético às instituições, no sentido de sistematizar as habilidades e as competências que os egressos irão desenvolver. Registramos que tais construções, abstratas e ideais, se distanciam, e muito, da realidade vivida em sala de aula. As estatísticas, os relatórios e os exames diversos, comuns no processo de avaliação dos cursos, sejam de graduação ou mesmo fundamental e médio, são insuficientes para evidenciar as condições de desenvolvimento dos estudantes.
} 
do estudo, ou da construção do conhecimento, é a marca da educação de rebanho que, aliás, acreditamos que não dispõe de construção possível.

A educação aristocrática não pode prescindir da construção de novos valores, ao contrário da educação de rebanho. Aliás, Nietzsche assinala que "o fato de que a massa seja enganada, por exemplo, em qualquer democracia, é extremamente significativo: deseja-se tornar o homem menor e mais governável: isto é considerado como sendo "progresso"” (NIETZSCHE, 2007, p. 215). A pequenez do humano justifica o seu aprisionamento no mundo, e o Estado, por meio de seus agentes, aproveita-se dessa peculiaridade, que é própria da natureza humana, para determinar os rumos da sociedade, demarcados pela ignorância, pela apatia e pelo adormecimento. Melo Sobrinho (2007) afirma que:

\begin{abstract}
Segundo Nietzsche, a gregaridade é o fenômeno mais antigo e mais determinante da história da humanidade, e fora do qual o homem tal como o conhecemos não poderia ser absolutamente compreendido. Em outras palavras, a comunidade é a condição irrevogável da vida dos homens, e os instintos gregários foram por isso aqueles que neles se desenvolveram com mais regularidade e constância, e sempre estiveram na base das suas ações e das suas inclinações mais fortes, em detrimento mesmo da sua individualidade. Portanto, a própria dimensão política na qual o homem foi sempre instado só pode ser explicada quando relacionada com esta sua sociabilidade originária (MELO SOBRINHO, 2007, p. 11, grifo da tradutora).
\end{abstract}

Nesse sentido, sendo a comunidade a base da gregaridade, então, temos um indício da educação de rebanho e da recusa à individualidade. Em outro trecho de sua apresentação, Melo Sobrinho (2007) continua a falar do sentido comunitário:

[...] no decorrer do tempo, a cristalização de hábitos e costumes traz como resultado a estagnação e embrutecimento da cultura, pois impede o surgimento daqueles homens desvinculados, independentes e moralmente fracos de quem depende de resto o progresso, condenando-os muitas vezes ao desaparecimento. A onipresença do Estado, por sua vez, fulmina a possibilidade de surgimento do indivíduo, e desse modo impede a mudança, esteriliza o progresso e torna a vida social estagnada e decadente (MELO SOBRINHO, 2007, p.16, grifos da tradutora).

Vemos que os resultados da vida comunitária se traduzem pelo enfraquecimento do indivíduo e até pela possibilidade de sua morte. É nesse contexto que Nietzsche defende o aristocratismo e que nós defendemos a importância da educação aristocrática, em contraposição à vigente educação de rebanho.

A natureza humana como pequena e mesquinha exprime a segunda razão pela qual o homem se mantém no estado de adormecimento. Não se trata de aniquilar a educação de rebanho pelo que ela deixa de promover ou pelo que promove, isto é, a massificação. Ela é o 
pressuposto da educação aristocrática, e esse paradoxo legitima a reivindicação de Nietzsche que se segue:

- Ó espíritos livres, posso vos dizer isso em alta voz? Criar, mas também utilizar as circunstâncias que tornariam possível a sua vinda; explorar e trilhar os caminhos que conduziriam de tal maneira uma alma a este grau de elevação e de firmeza, que ela sentiria a necessidade destas tarefas; forjar, através de uma inversão dos valores, os corações e as consciências de bronze, capazes de suportar o peso de uma tal responsabilidade; enfrentar, por outro lado, ao mesmo tempo, a necessidade de tais comandantes e o risco assustador de que eles viessem a faltar ou que fracassassem e degenerassem - estas são as nossas preocupações e as nossas angústias, vós o sabeis, espíritos livres, estes são os pensamentos longínquos que rasgam como uma tempestade o céu de nossa vida (NIETZSCHE, 2007, p. 204, grifos do autor).

Esta reivindicação expurga a pequenez do homem e certamente combate o seu aprisionamento; entretanto, quem é o espírito livre na sociedade? 'Seu 'conhecimento' é criação, sua criação é legislação, sua vontade de verdade é vontade de poder. - Existem hoje estes filósofos? Já houve estes filósofos? Não é preciso que haja estes filósofos?" (NIETZSCHE, 2007, p. 303, grifos do autor). Sim, é necessário requisitar esses filósofos para a revaloração de valores. A educação aristocrática aponta para esse tipo de indivíduo, capaz de superar a mesquinharia e a pequenez humanas. Nas palavras de Nietzsche, o homem livre irá:

[...] ensinar o futuro do homem como sua vontade, um futuro que será dependente da sua vontade, para realizar grandes empreendimentos de educação e seleção, e com isso pôr um fim a esse terrível domínio absurdo e do acaso que foi até agora chamado de "história" - o absurdo do "maior número" é apenas a sua última forma de expressão -: para o cumprimento desses atos, seria preciso haver um dia uma nova espécie de filósofos comandantes, diante dos quais todos os espíritos ocultos, terríveis, benévolos, parecerão pálidos e mesquinhos (NIETZSCHE, 2007, p. 203, grifos do autor).

Portanto, como resultado da educação aristocrática, o homem deixará de ser pequeno e mesquinho, e isso partirá de sua vontade. Trata-se, assim, da vida solitária, que proporciona ao indivíduo, por meio da solidão, o contato dele consigo e a experiência de superação de seu estado de massificação e adormecimento. A educação aristocrática aponta para a grande individualidade, em contraposição à maioria das pessoas. Há outros elementos que justificam o adormecimento do homem no mundo; contudo, a sinalização feita até o presente parece-nos suficiente para evidenciar o nascedouro da educação aristocrática em Nietzsche. Paradoxalmente, a educação aristocrática é pensada também a partir da educação de rebanho. A "cegueira" da educação de massa anuncia a busca da solidão, na medida em que o aristocrata opta pela vida solitária, que se contrapõe ao rebanho. 


\section{CONSIDERAÇÕES FINAIS}

O aristocratismo, como vimos, contrapõe-se ao espírito gregário, da mesma forma que a educação aristocrática se confronta com a educação de rebanho; entretanto, esse antagonismo é importante para os dois tipos de educação. O que seria da educação de rebanho sem a educação aristocrática e vice-versa? Queremos sublinhar mais uma vez que está longe da proposição do aristocratismo de Nietzsche, e mesmo da educação aristocrática, o exaurimento do espírito gregário. O sentido da educação de rebanho está na produção de terreno fértil para a crítica cuidadosa de uma educação que revela a natureza humana.

O aristocratismo está longe de consumar-se em proposição teórica, na medida em que o filósofo da vontade de potência remete a encarnações históricas de aristocracia. Comentando o aristocratismo de Nietzsche, Marton (2006) afirma que:

O homem nobre a que se refere não se reduz a mero conceito; em contextos muito
precisos, acredita deparar com ele. Julga que existiu nos séculos XVII e XVIII com
a nobreza francesa, no Renascimento com a comunidade aristocrática de Veneza e,
sobretudo, na Antiga Grécia, com a aristocracia guerreira. Então, conceber a
existência como um duelo leal era condição inerente ao forte. Não se podia guerrear
quando se desprezava e não havia por que fazê-lo quando se dominava. Para que
houvesse o confronto, era preciso que existissem antagonistas; para que perdurasse,
era necessário que os beligerantes não fossem aniquilados (MARTON, 2006, p. 50).

Assim, o sentido do aristocratismo está na possibilidade do conflito, lei natural, da mesma forma que a educação aristocrática. Com essa análise de Marton sobre Nietzsche, observamos mais uma vez a influência dos escritos de Heráclito de Éfeso, inspirador do filósofo da vontade de potência, especialmente quando afirma que da luta dos contrários nasce a mais bela harmonia (cf. MENDONÇA, 1999). Como já enfatizamos, não se trata da anulação de forças, mas da sua constante superação, que se dá na oposição. É interessante considerar as palavras de Nietzsche, abaixo, que tratam da superação:

Para os espíritos superiores, não é pequeno o perigo de que eles aprendam um dia ou outro a buscar novamente as alegrias terríveis que residem em destruir, em demolir pedra por pedra, situação na qual a ação criadora lhes permaneceria absolutamente interdita, na ausência de instrumentos ou por qualquer outro capricho cruel do acaso (NIETZSCHE, 2007, p. 337).

Notamos que, para o aristocrata, a possibilidade de destruição, de demolição e da degenerescência do construído é tarefa cotidiana; por essa via ele faz constantemente a superação que propicia a revaloração de valores.

A educação aristocrática em Nietzsche trata da educação da grande e nobre individualidade e, em última instância, refere-se à educação do indivíduo solitário: uma 
educação para os espíritos livres e que estejam dispostos a empreender a autocrítica para exercer a sua liberdade por meio da autossuperação. Portanto, os elementos que fundamentam a educação aristocrática não se resumem às condições do vulgo; dizem respeito, precisamente, ao anúncio do homem do futuro, muito livre.

\section{REFERÊNCIAS}

ALMEIDA, R M. Vontade de crueldade nos escritos trágicos de Nietzsche. Filosofia Unisinos, v. 9, n. 2, maio/ago. 2008.

MARTON, S. Nietzsche: a transvaloração dos valores. 2. ed. São Paulo, SP: Moderna, 2006. 96p.

MELO SOBRINHO, N. C. Escritos sobre política: apresentação. São Paulo, SP: Loyola, 2007. vol. I. 360p.

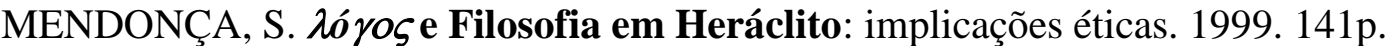

Dissertação (Mestrado) - Pontifícia Universidade Católica de Campinas, Campinas, 1999.

NIETZSCHE, F. Escritos sobre Política. Trad. Noéli Correia de Melo Sobrinho. São Paulo: Loyola, 2007, vol. I. 360p.

Euvres philosophiques complètes. Giorgio Colli et Mazzino Montinari. Paris:

Gallimard, 1988. (v. 1-15).

Jenseits von Gut und Böse. Berlin: Goldmann, 1999. 334p.

Além do bem e do mal. Prelúdio a uma filosofia do futuro. Trad. Paulo César de Souza. São Paulo: Cia das Letras, 1992. 271p. 